LAWRENCE LIVERMORE N A TION AL LABORATORY

\title{
On the Violence of High Explosive Reactions
}

Craig M. Tarver, Steven K. Chidester

February 17, 2004

2004 ASME Pressure Vessels \& Piping Conference San Diego, CA, United States

July 25, 2004 through July 29, 2004 
This document was prepared as an account of work sponsored by an agency of the United States Government. Neither the United States Government nor the University of California nor any of their employees, makes any warranty, express or implied, or assumes any legal liability or responsibility for the accuracy, completeness, or usefulness of any information, apparatus, product, or process disclosed, or represents that its use would not infringe privately owned rights. Reference herein to any specific commercial product, process, or service by trade name, trademark, manufacturer, or otherwise, does not necessarily constitute or imply its endorsement, recommendation, or favoring by the United States Government or the University of California. The views and opinions of authors expressed herein do not necessarily state or reflect those of the United States Government or the University of California, and shall not be used for advertising or product endorsement purposes. 


\title{
ON THE VIOLENCE OF HIGH EXPLOSIVE REACTIONS
}

\author{
Craig M. Tarver and Steven K. Chidester \\ Lawrence Livermore National Laboratory \\ P.O. Box 808, L-282, Livermore, CA 94551
}

\begin{abstract}
High explosive reactions can be caused by three general energy deposition processes: impact ignition by frictional and/or shear heating; bulk thermal heating; and shock compression. The violence of the subsequent reaction varies from benign slow combustion to catastrophic detonation of the entire charge. The degree of violence depends on many variables, including the rate of energy delivery, the physical and chemical properties of the explosive, and the strength of the confinement surrounding the explosive charge. The current state of experimental and computer modeling research on the violence of impact, thermal, and shock-induced reactions is reviewed.
\end{abstract}

\section{INTRODUCTION}

High explosive safety and performance are two of the most important research areas in the field of energetic materials. Gaseous, liquid and solid high explosives are used throughout the world for many applications and must be stored as safely as possible until they are used. Then they must perform exactly as intended. There are many possible hazards to which high explosives may be subjected, but in general these hazards fall into three categories. The most frequent category is impact ignition of an exothermic chemical decomposition reaction caused by frictional and/or shear heating. Examples of this category are: dropping an explosive charge; dropping an object onto an explosive charge; sliding an explosive charge along a rough surface; relatively low velocity impacts by bullets and projectiles; and other mechanical accidents that cause displacement between an explosive charge and another object. The explosive charges may be bare (unconfined), weakly confined by thin case, or heavily confined by a thick case. The resulting reaction varies from a benign "puff" of gaseous reaction products to a fairly violent explosion.

The second category involves thermal heating the explosive charge to the temperature at which the exothermic chemical reaction overcomes the ability of the explosive charge to dissipate the applied heat. Then a "thermal explosion" or "runaway reaction" occurs. The violence of a thermal event depends upon the heating rate, the physical and chemical properties of the explosive, and the degree of confinement present. As for the impact category, the resulting reaction violence ranges from a weak venting of the confinement to a violent explosion. Following the initial chemical reactions, the subsequent result is either a failing reaction that does not propagate or a self-propagating reaction that consumes the entire charge. These self-propagating reactions generally range from unconfined burning of the charge to confined pressure-controlled deflagration. Both of these burning processes are subsonic and relatively non-violent. However, in confined geometries, there are scenarios that can result in compression and/or shock wave formation and even in the transition to a supersonic detonation wave. Detonation is the fastest energy release process for an explosive and thus is by far the most violent. Such scenarios are known as XDT (originally for Unknown Detonation Transition) and DDT (Deflagration to Detonation Transition).

The third category is shock initiation in which a supersonic shock wave impacts an explosive charge. If the strength and time duration of this shock wave (or waves) are sufficient, the chemical decomposition induced in the charge can cause the pressure and temperature to build up so rapidly that the initial shock wave is accelerated to detonation velocity and pressure in a process known as SDT (Shock to Detonation Transition). SDT is the intended result of an intentional firing of a train of explosive charges, but must be avoided at all costs in accident scenarios. Examples of SDT include initiation by a detonation wave of an adjacent charge and shock compression by a high velocity fragment or projectile. The attainment of a steady state detonation wave is the most violent chemical energy release possible from a high explosive.

In the area of computer modeling, the Ignition and Growth and Statistical Hot Spot hydrodynamic reactive flow models have been used to predict reaction violence for all three safety categories, and examples of these applications are discussed.

In this paper, it is impossible to discuss all of the possible scenarios and the resulting violence of the induced explosive reactions, but the current states of experimental, theoretical, and computer code modeling research for the three general categories (impact, thermal, and shock) at Law rence Livermore National Laboratory (LLNL)are reviewed. References are provided for more detailed explanations for various scenarios from each of the three safety categories. 


\section{NON-SHOCK IMPACT IGNITION}

When a heterogeneous solid explosive charge is subjected to a low velocity impact that produces only a few kilobars pressure, a two-stage compression wave is formed. This wave consists of an elastic wave that propagates through the explosive at longitudinal sound velocity followed by a plastic wave traveling at the lower plastic sound velocity $(1,2)$. Within the flow field produced by the plastic wave, regions of the explosive can be heated by void collapse, friction, shear, dislocation pile-up, and other dissipative mechanisms (3). There is not sufficient energy deposited in the high explosive charge to cause exothermic chemical decomposition in the entire charge, but locally heated regions called "hot spots" are formed that can ignite and grow into a violent energy release. Most of these ignitions result in subsonic deflagration waves driven by heat transfer from the hot reaction products into the surrounding explosive molecules. Impact ignition is one of the most important safety concerns, because it is caused by dropping, rough handling, or poor protection of explosive charges in industrial and laboratory situations.

Several qualitative tests have been developed to study specific impact scenarios: drop hammers; drop weight impact machines; the Skid test; the Susan test; etc. In recent years, the Steven Test at Lawrence Livermore National Laboratory (LLNL) (4-11) and its modified version at Los Alamos National Laboratory (LANL) (12-14) have yielded quantitative experimental data that can be simulated with reactive flow computer models. Figure 1 shows the LLNL version of the Steven Test in which $11 \mathrm{~cm}$ diameter by $1.285 \mathrm{~cm}$ thick cylindrical high explosive charges are tightly confined by a Teflon ring and impacted by $6.01 \mathrm{~cm}$ diameter steel projectiles with various radii of curvature. Five different projectiles have been tested thus far to simulate various accident scenarios. In the LANL version, this Teflon ring is not used allowing the explosive charge to deform upon impact. Thus the two versions test two types of confinement (strong and weak) typically used with high explosives. Several techniques, including embedded pressure gauges, exterior strain gauges, ballistic pendulums, and blast overpressure gauges, have been employed to measure the violence of the reactions produced in these Steven Tests (7-12). Thus far, several octahydro-1,3,5,7tetranitro-1,3,5,7-tetrazocine (HMX) based plastic bonded explosives (PBX's) have yielded distinct threshold projectile impact velocities for reaction in both versions. This is not true for other impact safety tests, whose thresholds are reported as values for which $50 \%$ of the tests caused observable reactions. The threshold velocities are slightly higher for the unconfined explosive charges in the LANL test, since the explosives can flow away from the impact area. These threshold velocities fall in the usual order of impact sensitivity with PBX 9404 (94\% HMX, $3 \%$ nitrocelluose, 3\% binder) being the most sensitive and EDC-37 (91\% HMX, 8\% K10 oil, 1\% nitrocelluose) the least sensitive of the HMX-based materials tested. The insensitive high explosive 1,3,5-triamino-2,4,6trinitrobenzene (TATB) based high explosives has never reacted in the Steven Test or any other impact test (4). The measured violence of reaction increases with projectile velocity in both versions, but remains well below that of an intentional detonation of a Steven Test charge. The embedded pressure gauge records measure input pressures of less than $0.1 \mathrm{GPa}$ and pulse durations of approximately $60 \mu \mathrm{s}$. The measured times to reaction are 200 to $500 \mu \mathrm{s}$. Blast overpressure gauges typically record $1-4$ psi pressures 10 feet from the explosive target, whereas intentional detonations of targets containing similar explosive masses produce $12-14$ psi overpressures (4-6)). Thus the reactions produced in the Steven impact tests are deflagration waves which consume the 225 gram charges in seconds. Damaged HMX explosives exhibit slightly lower threshold velocities and slightly more violent reactions $(6,7)$, because deflagration waves propagate more rapidly through the cracks in the damaged charges. Since the main ignition mechanisms appear to be friction and shear at the explosive - metal interfaces, heated HMX explosive targets, which become less stiff and mechanically weaker, actually exhibit higher threshold velocities for impact ignition (10). Aged HMX-based explosives have approximately the same threshold velocities as newly prepared charges (5-7). The two Steven Tests have furnished the required data for predictive reactive flow modeling.

FIGURE 1. Geometry of the LLNL Steven Impact Test

The measured pressures, pulse durations, and times to reaction, as well as the threshold velocities for ignition for several projectile types, have been calculated by the Ignition and Growth reactive flow model (6-9). As discussed in the next section, this model was originally developed for shock initiation and detonation predictions, but has been applied to other reactive flows, such as XDT (fracture-recompaction ignition-detonation transition)(15), pressure dependent deflagration(16), and deflagration-to-detonation transition (DDT). Normalizing the Ignition and Growth model to Steven Test data has for the first time enabled predictions to be made of impact ignition thresholds in accident scenarios that can not be tested. The model accurately predicts the change in threshold velocities as different projectile geometries are used (9). Several ignition mechanisms (frictional work, shear, pore collapse, strain rate effects, etc.) have used within the Ignition and Growth model framework to account for the onset of exothermic reaction in impact induced "hot spots." The mechanical strength model used to describe the unreacted explosive is extremely important for modeling these low pressure, long time duration impact scenarios. Presently, it is not clear which physical mechanism (or mechanisms) dominates the "hot spot" formation and ignition process 
under each set of impact conditions. Precise experiments in which one of more of these energy dissipation mechanisms is eliminated (or at least greatly reduced) are needed to better understand non-shock impact ignition.

\section{THE IGNITION AND GROWTH REACTIVE FLOW MODEL}

All reactive flow models require as a minimum: two equations of state, one for the unreacted explosive and one for its reaction products; a reaction rate law for the conversion of explosive to products; and a mixture rule to calculate partially reacted states in which both explosive and products are present. The Ignition and Growth reactive flow model (17) uses two Jones-Wilkins-Lee (JWL) equations of state, one for the unreacted explosive and another one for the reaction products, in the temperature dependent form:

$$
\mathrm{p}=\mathrm{A} \mathrm{e}^{-\mathrm{R}_{1} \mathrm{~V}}+\mathrm{B} \mathrm{e}^{-\mathrm{R}_{2} \mathrm{~V}}+\omega \mathrm{C}_{\mathrm{V}} \mathrm{T} / \mathrm{V}
$$

where $p$ is pressure in Megabars, $V$ is relative volume, $T$ is temperature, $\omega$ is the Gruneisen coefficient, $\mathrm{C}_{\mathrm{V}}$ is the average heat capacity, and $\mathrm{A}, \mathrm{B}, \mathrm{R}_{1}$ and $\mathrm{R}_{2}$ are constants. The unreacted explosive equation of state is fitted to the available shock Hugoniot data, and the reaction product equation of state is fitted to cylinder test and other metal acceleration data. At the high pressures involved in shock initiation and detonation of solid and liquid explosives, the pressures of the two phases must be equilibrated, because interactions between the hot gases and the explosive molecules occur on nanosecond time scales depending on the sound velocities of the components. Various assumptions have been made about the temperatures in the explosive mixture, because heat transfer from the hot products to the cooler explosive is slower than the pressure equilibration process. In this version of the Ignition and Growth model, the temperatures of the unreacted explosive and its reaction products are equilibrated. Temperature equilibration is used, because heat transfer becomes increasingly efficient as the reacting "hot spots" grow and consume more explosive particles at high pressure and temperature. The reaction rate equation is:

$$
\begin{aligned}
& \mathrm{dF} / \mathrm{dt}=\mathrm{I}(1-\mathrm{F})^{\mathrm{b}}\left(\rho / \rho_{\mathrm{o}}-1-\mathrm{a}\right)^{\mathrm{x}}+\mathrm{G}_{1}(1-\mathrm{F})^{\mathrm{c}} \mathrm{F}^{\mathrm{d}} \mathrm{p}^{\mathrm{y}}+\mathrm{G}_{2}(1-\mathrm{F})^{\mathrm{e}} \mathrm{F}^{\mathrm{g}} \mathrm{p}^{\mathrm{Z}} \\
& 0<\mathrm{F}<\mathrm{F}_{\text {igmax }} \quad 0<\mathrm{F}<\mathrm{F}_{\mathrm{G} 1 \max } \quad \mathrm{F}_{\mathrm{G} 2 \min }<\mathrm{F}<1
\end{aligned}
$$

where $\mathrm{F}$ is the fraction reacted, $\mathrm{t}$ is time in $\mu \mathrm{s}, \rho$ is the current density in $\mathrm{g} / \mathrm{cm}^{3}, \rho_{\mathrm{o}}$ is the initial density, $\mathrm{p}$ is pressure in Mbars, and $\mathrm{I}_{1} \mathrm{G}_{1}, \mathrm{G}_{2}$, a, b, c, d, e, g, x, y, z, $\mathrm{F}_{\mathrm{igmax}}, \mathrm{F}_{\mathrm{G} 1 \max }$, and $\mathrm{F}_{\mathrm{G} 2 \min }$ are constants. This three-term reaction rate law represents the three stages of reaction generally observed during shock initiation and detonation of pressed solid explosives (17). The first stage of reaction is the formation and ignition of "hot spots" caused by the various possible mechanisms discussed for impact ignition as the initial shock or compression wave interacts with the unreacted explosive molecules. Generally the fraction of solid explosive heated during shock compression is approximately equal to the original void volume. For shock initiation modeling, the second term in Eq. (2) then describes the relatively slow process of the inward and/or outward growth of the isolated "hot spots" in a deflagration-type process. The third term represents the rapid completion of reaction as the "hot spots" coalesce at high pressures and temperatures, resulting in a transition to detonation. For detonation modeling, the first term again reacts a quantity of explosive less than or equal to the void volume after the explosive is compressed to the unreacted von Neumann spike state. The second term in Eq. (2) is used to model the fast decomposition of the solid into stable reaction product gases $\left(\mathrm{CO}_{2}, \mathrm{H}_{2} \mathrm{O}, \mathrm{N}_{2}, \mathrm{CO}\right.$, etc.). The third term is used to describe the relatively slow, diffusion limited formation of solid carbon (amorphous, diamond, or graphite) as the equilibrium Chapman-Jouguet (C-J) is approached. All of these reactive processes have been observed experimentally using embedded gauges and laser interferometric techniques. To model pressure dependent deflagration processes, a version of Ignition and Growth called DYNABURN was developed in the first (compressive ignition) reaction rate in Eq. (2) is removed. A small value of fraction reacted and/or pressure is then placed in the region of the explosive charge mesh where reaction first occurs, and the second and third reaction rate terms then propagate a subsonic deflagration rate through the rest of the explosive charge. DYNABURN has been applied to various high-pressure deflagration problems including interior ballistics, air bag and other propellants, and explosive burns (16).

The Ignition and Growth reactive flow model has been applied to a great deal of experimental shock initiation and detonation data using several one-, two-, and three-dimensional hydrodynamic codes. In shock initiation applications, it has successfully calculated many embedded gauge, run distance to detonation, short pulse duration, multiple shock, reflected shock, ramp wave compression, and divergent flow experiments on several high explosives at various initial temperatures (heating plus shock scenarios), densities, and degrees of damage (impact plus shock scenarios). For detonation wave applications, the model has successfully calculated embedded gauge, laser interferometric metal acceleration, failure diameter, corner turning, converging, diverging, and overdriven 
experiments.

For the Steven Impact Test, Figures 2 and 3 show the experimental and calculated pressure histories for two experiments using the HMX-based explosive PBX 9501 (95\% HMX, 2.5\% nitroplasticizer, 2.5\% Estane binder). In Fig. 2, the impact velocity of a type 1 projectile was $51.36 \mathrm{~m} / \mathrm{s}$ and no reaction was observed or predicted by the calculations. The measured peak pressure was about $0.08 \mathrm{GPa}$ and it lasted 60 microseconds. Figure 3 shows similar pressure histories for an impact velocity of $55.4 \mathrm{~m} / \mathrm{s}$, which did produce reaction in the PBX 9501 after $400-600$ microseconds. Good agreement between the pressure gauges and the calculations in terms of the initial peak pressure, pulse duration, and time to violent reaction has been obtained for several projectile shapes (10).

FIGURE 2. Experimental and calculated pressure histories in a PBX 9501 Steven Test target impacted at $51.36 \mathrm{~m} / \mathrm{s}$

FIGURE 3. Experimental and calculated pressure histories in a PBX 9501 Steven Test target impacted at $55.40 \mathrm{~m} / \mathrm{s}$

\section{VIOLENCE OF THERMAL EXPLOSIONS}

The ability to predict the time to exothermic chemical reaction and the violence of the subsequent explosion is essential to accident scenarios involving fires, heating by lasers and particle beams, and combined scenarios involving heat plus impact or shock. The ability to predict time to and location of thermal explosion in confined and unconfined explosive charges is based on developing reactive heat transfer models of chemical decomposition. These models incorporate the available experimental data on times to explosion, heat conduction, specific heats, and chemical kinetics of the reactions involved in the decomposition process. Global mechanisms based on $3-5$ reactions have successfully predicted times to explosion over wide ranges of explosive properties, temperatures, heating rates, and degrees of confinement (18). The four-step global reaction sequence for HMX decomposition is:

$\begin{array}{lcc}\text { Beta HMX } & ----> & \text { Delta HMX } \\ \text { Delta HMX } & ----> & \text { Solid Intermediates } \\ \text { Solid Intermediates } & ----> & \text { Gaseous Intermediates }\left(\mathrm{CH}_{2} \mathrm{O}, \mathrm{N}_{2} \mathrm{O}, \mathrm{HCN}, \mathrm{HNO}_{2}, \text { etc. }\right) \\ \text { Gaseous Intermediates } & ----> & \text { Final Products }\left(\mathrm{CO}_{2}, \mathrm{H}_{2} \mathrm{O}, \mathrm{N}_{2}, \mathrm{CO}, \mathrm{C}, \text { etc. }\right)\end{array}$

Figure 4 shows the experimental and calculated times to explosion for coarse and fine particle HMX measured for $1.27 \mathrm{~cm}$ diameter spheres in the One Dimensional Time to Explosion (ODTX) apparatus at $1.5 \mathrm{kbar}$ confinement pressure (19).

Figure 4. ODTX Experimental and Calculated Times to Explosion versus Inverse Temperature for Coarse and Fine HMX Particles

Measuring and predicting the degree of violence of thermal explosion is much more difficult. The violence of a thermal explosion for a particular explosive depends on the heating rate and the degree of confinement. If an explosive is heated very rapidly, the relative low thermal conductivity of the organic explosive molecule limits the heat transfer into the charge, and "runaway" exothermic chemical reaction occurs near the outer boundary. Since only the outer part of the explosive charge is involved in producing the gaseous reaction products that overcome the surrounding confinement strength, the resulting explosion is relatively non-violent. With very insensitive explosives like TATB, unreacted material is recovered. At slower heating rates, the external heat is conducted deeper into the charge and the runaway reaction occurs at or near the center of the charge. Most of the explosive reacts before the confinement is breached and the resulting explosion is more violent. At very slow heating rates, the explosions become less violent, because enough gas is generated by slow decomposition to overcome the confinement strength before runaway reactions can occur. This feature of thermal explosion violence has been known for a long time. However, quantifying the violence of thermal explosion experimentally and computationally has only been possible for the last few years.

The first quantitative measurements of the violence of thermal explosion at LLNL were reported by Chidester et al. (16). Twenty large heavily confined cylinders of HMX- and TATB-based explosives were heated to thermal explosion at rates varying from $2^{\circ} \mathrm{C}$ per minute to $3.3^{\circ} \mathrm{C}$ per hour. Fourteen of the explosive cylinders were hollow, and inner metallic liners with small heaters attached were used to produce uniform temperatures throughout the charge just prior to explosion. A complex thermocouple pattern measured the temperature histories and determined the approximate region of the first runaway reaction. The violence of the explosion was measured by velocity pin arrays placed inside and outside the metal confinement cylinders, flash X-rays, overpressure gauges, and fragment 
collection techniques. Some cylinders were intentional detonated to provide violence comparisons. The times to and locations of thermal explosion were accurately by the chemical decomposition models for HMX and TATB. DYNABURN was then used to calculate the collapse of the inner metal cylinders and expansion of the outer steel cylinders. The most violent HMX thermal explosions gradually accelerated the outer cases to velocities approaching those produced instantaneously by intentional detonation approximately $120 \mu$ s after the onset of explosion. The measured and calculated inner cylinder collapse velocities were much lower than those produced by detonation. The TATB-based high explosive LX-17 (92.5\% TATB and 7.5\% KelF binder) produced no violent thermal explosions, and large quantities of unreacted TATB were recovered after the tests. This is not surprising because measured TATB deflagration rates are at least an order of magnitude slower than those of HMX (16).

Four additional experiments have since been developed at LLNL to supply the required data needed for predictive modeling of the violence of thermal explosion. Two of these tests measure the deflagration rates of high explosives under high-pressure conditions. The hybrid strand burner (20) ignites pre-pressurized cigarette size explosive samples and measures the evolving deflagration velocities as the internal pressure rises. The time of arrival pins in this apparatus can measure deflagration velocities at pressures approaching $1 \mathrm{GPa}$. For deflagration velocities at the higher pressures produced during DDT and SDT scenarios, high explosives samples are pressurized in a Diamond Anvil Cell (DAC) apparatus and then ignited by a pulsed laser. A streak camera is used to measure the propagation velocity of the resulting subsonic deflagration rate. Very sensitive high explosives such as pentaerythritol tetranitrate (PETN) transition from relatively slow velocities (tens of meters per second) to very fast velocities (a thousand meters per second) at some pressure, while HMX rates gradually increase form tens to hundreds of meters per second at detonation-like pressures (21). TATB explosives never deflagrate more rapidly than 20 meters per second even at detonation-like pressures (22). These measured high-pressure deflagration rates are used directly in DYNABURN and more complex hot spot growth models (23-25).

The other two experiments involve thermal explosion. The Scaled Thermal Explosion Test (STEX) (26) employs one-, two- or four-inch diameter cylinders of high explosives confined by steel tubes of various thicknesses and strengths. The cylinders are heated very slowly (usually $1{ }^{\circ} \mathrm{C}$ per hour after an initial faster ramp and soak time) to insure uniform temperatures and the most violent possible thermal explosions. Thermocouples, strain gauges, and micro-power radar horns are used to measure the temperature, strain, and steel confinement velocity histories, respectively. A STEX test often requires several days before explosion occurs, but the times to explosion are accurately calculated by the global decomposition models (19). Most of the STEX tests on HMX-based explosives have produced relatively non-violent deflagration reactions in which the steel confinement is accelerated to velocities far less than those produced by intentional detonations and fragments of steel are recovered. However, some STEX tests have produced high fragment velocities and very little of steel was recovered. Thus thermal explosions, while not even partially detonating, can accelerate confinement fragments to velocities over 1000 meters per second.

A case fragment formed and accelerated by thermal explosion may be of sufficient energy and size to cause XDT or SDT of a neighboring cased or bare explosive charge upon impact. Such an accident scenario is sometimes called "sympathetic detonation" or "nearby explosion." To qualify the momentum produced in a neighboring explosive charge by a thermal explosion, the "Jerry" Test was developed (27-29). In this test, a heavily confined donor explosive charge is heated to thermal explosion relatively rapidly (in an hour or two) using thermocouples to measure temperature and explosion location and external pins to measure the resulting confinement motion. An acceptor charge with embedded pressure gauges is placed either in contact with the steel confinement or a few centimeters away from the steel confinement to allow the accelerating steel to reach its maximum velocity prior to impact. The embedded gauges show that ramp wave compressions that require tens of microseconds to reach maximum pressures of approximately $0.5 \mathrm{GPa}$ are produced in the acceptor charges in contact with the donor charges. Acceptor charges separated from the donor charges are impacted at several hundred meters per second after thermal explosion of the most energetic HMX charges, which deflagrate at several hundred meters per second as measured by the internal pins. These impacts produce shock pressures of approximately $1 \mathrm{GPa}$ in the acceptor charges. Generally this shock pressure is not sufficient to cause prompt reaction in HMX-based explosives. Figure 5 shows a comparison of the experimentally measured pressure histories at various depths in an acceptor charge of PBX 9501 (95\% HMX, 2.5\% nitroplastizer, 2.5\% Estane binder) and the Ignition and Growth shock initiation reactive flow model for PBX 9501. No chemical reaction is observed or predicted. Using LX-04 (85\% HMX and $15 \%$ Viton binder), which has not deflagrated faster than 100 meters per second in the burn tests mentioned above, the steel confinement of the Jerry Test was not accelerated by the weak thermal explosion. These Jerry Test results are furnishing essential data on pressures and fragments produced during thermal explosion events for use in reactive flow models that can predict the violence of scenarios that can not be tested directly in large, dangerous explosive charges.

Figure 5. Experimental and Calculated Pressure Histories in a PBX 9501 Acceptor Charge in the Jerry Test 


\section{WEAK SHOCK COMPRESSION}

At slightly higher pressures than those produced in impact and thermal explosion scenarios, elastic and plastic waves merge into a relatively weak shock wave $(1,2)$. For homogeneous explosives such as liquids without bubbles and perfect solid crystals, these shocks compress and heat the explosive molecules slightly, but little or no chemical decomposition occurs. For some heterogeneous solid explosives, there exists a narrow range of shock pressures in which all of the voids and other inhomogeneities can be compressed and perhaps react locally without creating growing hot spots. The critical hot spot temperatures required for sustained reaction in HMX and TATB based on the global chemical decomposition models (30) described above are illustrated in Fig. 6. The resulting fully dense explosive material can not be shock initiated by subsequent strong shock waves or even detonation waves. This phenomenon is called "dead pressing" or "shock desensitization." Depending on the application, this can be a useful or a frustrating property of explosive charges. In the most thorough study of shock desensitization, Campbell and Travis (31) demonstrated that weak shock waves in the pressure range of 1 to $2.4 \mathrm{GPa}$ could collapse the voids in PBX-9404 and Composition B-3, creating relatively homogeneous materials that failed to detonate when subjected to their own detonation waves. Interestingly, these detonation wave failures required times and run distances approximately equal to those measured for shock initiation by low amplitude shocks. Thus the detonation waves propagated until they reached material that had no more voids capable of forming new "hot spots." Tarver et al. (32) observed shock desensitization in the TATB-based explosive LX-17 in reflected shock experiments. They calculated the phenomena using the Ignition and Growth model by assuming that a certain range of compressions ( $\mathrm{h}$ $\left.<\left(\rho / \rho_{0}-1\right)<a\right)$ in the first term of Eq. (2) would result in no reaction ever occurring in the explosive. This assumption can not address the observed times required for detonation failure in shock desensitized explosives.

Figure 6. Critical Hot Spot temperatures for HMX and TATB at Various Diameters

A Statistical Hot Spot reactive flow model $(23,24)$ has been developed in the ALE3D computer code, which incorporates chemical-thermal-mechanical models within its hydrodynamic algorithms. This model treats distributions of hot spot sizes and temperatures that form upon shock compression. These hot spots can then either ignite or fail to ignite and subsequently growth or fail or grow into the surrounding explosive particles. The growth rates of the hot spots can be either pressure dependent based on the strain burner and DAC measurements or temperature dependent driven by heat transfer, as are all chemical reactions in real explosive grains. The Statistical Hot Spot model successfully calculated the time dependent shock desensitization of HMX (23) and TATB (24). This model represents the next generation of reactive flow models and will be eventually be applied to all the violence scenarios discussed in this paper. Yoh and McClelland (33) have begun using the temperature driven reaction rates in ALE3D to analyze the STEX test results. A grain scale model which individual grains of HMX and their binder layers are meshed, shocked and then reacted using the global thermal decomposition rates from thermal explosion has been developed in ALE3D for use on the large, fast ASCI computers by Reaugh (25). This nanoscale model has justified some of the geometric assumptions used in the macroscale Ignition and Growth model and has shed light on future reactive flow modeling directions.

\section{SHOCK INITIATION AND DETONATION OF HOMOGENEOUS EXPLOSIVES}

Homogeneous explosives include gases, liquids without bubbles or suspended solids, and perfect crystals of solid explosives. Since they contain no voids, binders or solid particles, they do not form hot spots when impacted at low velocities and thus do not easily ignite. They can be heated to thermal explosion like other explosives. In these materials, the main hazard scenario is shock initiation of detonation. Planar shock waves uniformly compress and heat the explosive molecules. If the shock temperature is high enough and lasts long enough, a thermal explosion occurs at or near the rear of the charge. This explosion creates a detonation wave that propagates through the precompressed explosive at a velocity greater than the eventual steady state Chapman-Jouguet (C-J) detonation velocity. This phenomenon is called "super detonation." When the "super detonation" wave overtakes the initial shock wave, it gradually decreases in velocity until it reaches the C-J value. Since the entire charge detonates, shock initiation of a homogeneous explosive is very violent. Little or none of a confining case can be removed after such as a detonation.

A much less violent but still industrially catastrophic accident called "low velocity detonation or LVD" can occur in shock sensitive liquids, such as nitroglycerine, confined in pipes made up materials that have higher sound velocities than that of the liquid explosive. If the pipe is subjected to a shock wave, the shock wave in the pipe material runs ahead of the shock in the liquid creating cavities (or bubbles). When the shock in liquid reaches these

cavities, they collapse creating hot spots and reaction sites. The resulting reactive wave can then propagate down the 
pipe at velocities slightly greater than the liquid sound velocity (about 2000 meters per second) consuming just the liquid near the collapsed cavities or, in the worst cases, transition to a fully reacting C-J detonation traveling at 6000 -8000 meters per second. To prevent LVD and the transition to full detonation, liquid energetic materials are now transported in non-metallic materials with low sound velocities.

\section{SHOCK INITIATION AND DETONATION OF HETEROGENEOUS EXPLOSIVES}

It has long been known that shock initiation of heterogeneous solid explosives (pressed or cast to densities close to their theoretical maximum densities) is controlled by ignition of hot spots (3). For shock waves that are strong enough that the solid elastic-plastic behavior is no longer important (1-2 GPa and higher), the initial shock front rapidly compresses the voids forming heated regions that may or may not ignite. Several hot spot formation mechanisms have been proposed, but rapid collapse of voids and jetting of unreacted explosive material across the closing into more unreacted material is the most likely mechanism. Perfect crystals and "shock desensitized" solid explosive containing no voids are extremely difficult or impossible to shock initiate. Again Fig. 6 shows calculated critical spherical hot spot temperatures for various diameter hot spot sizes in HMX and TATB. Once ignited, the reacting hot spots may grow into neighboring solid explosive particles or they may fail to grow due to heat losses by thermal diffusion. This growth process may take several microseconds and thus occurs well behind the leading shock front. The pressure and temperature increase rapidly in the reaction zone and a pressure wave develops. As the growing hot spots coalesce at high pressures and temperatures, this pressure wave overtakes the initial shock wave and transition from shock induced reaction to detonation occurs very rapidly. The distance at which the initial shock wave transitions to a detonation wave decreases as the strength of the initial shock wave increases. The violence of a shock-induced reaction in a heterogeneous solid explosive thus depends on the strength and time duration of the shock pulse (or pulses). If the shock pressure is low but it lasts for a long enough time, the reactive flow it produces may not be able to buildup to full detonation in the finite dimensions of the explosive charge. The resulting reaction creates a great deal of hot, high-pressure gas but is not violent as a detonation wave. If the buildup to detonation takes most of the charge, then only a partial detonation occurs. If the shock pressure is too low and/or the pulse duration is too short, the shock may cause some initial reaction but the wave will fail to grow to detonation and the reaction violence will be low. Of course, if the shock pressure is very high, full detonation and its accompanying violence promptly occur. Experimental chambers and large explosive handling facilities are built to withstand full detonation of the maximum allowed explosive weight. Facilities handling multiple explosive charges contain barriers to protect other charges from the blast and fragments produced by accidental detonation of a neighboringcharge.

The buildup of pressure and particle velocity behind the shock wave front during shock initiation has been thoroughly studied using embedded gauge $(34,35)$ and laser interferometric (36) techniques. These reactive flows have been modeled in several multidimensional codes using the Ignition and Growth model of shock initiation and detonation (37). Figure 7 shows measured and calculated particle velocity histories obtained for a shock initiation experiment on the TATB-based explosive LX-17 (34). The first term in the reaction rate law shown in Eq. (2) is used to account for the increase in shock front pressure recorded by the gauges in Fig. 7. The second or growth term in Eq. (2) is then used to simulate the growth of reaction behind the shock front, which causes the maximum particle velocities in Fig. 7. The third or completion term then models the rapid transition to detonation shown on the last three gauge records in Fig. 7. This rapid transition occurs when the growing hot spots are large enough to interact and rapidly transfer large amounts of heat to the remaining explosive particles.

FIGURE 7. Particle velocity histories for LX-17 shock initiated by a Kel-F flyer plate at $2.951 \mathrm{~mm} / \mu \mathrm{s}$

Detonation wave reaction zone structures in solid explosives and their metal acceleration properties have also been measured by embedded gauges and laser interferometry and calculated by the Ignition and Growth model (38). Figure 8 shows the measured and calculated interface velocity histories for detonating LX-17 impacting various salt crystals (38). The von Neumann spike state, a relatively fast reaction, a slower reaction, and finally the initial expansion of the products are clearly evident in Fig. 8. Figure 9 illustrates the measured and calculated free surface velocities of $0.267 \mathrm{~mm}$ thick tantalum discs driven by $19.871 \mathrm{~mm}$ of detonating LX-17. The momentum associated with the LX-17 reaction zone, which is approximately $3 \mathrm{~mm}$ long, and early product expansion are accurately measured and calculated in these small-scale experiments. The larger copper cylinder test is generally used to measure more of the reaction product expansion process. Since the main use of detonating solid explosives is to accelerate metals and other materials to high velocities, accurate measurements of the unreacted shock state (the "von Neumann spike"), the pressure profile of the chemical reaction zone, and the subsequent expansion of the reaction products as they deliver their momentum to the metal are essential. Currently these properties are known to 
within a few percent with nanosecond resolution (39). Improved accuracy and time resolution are future experimental and computational goals.

FIGURE 8. Interface particle velocity histories for detonating LX-17 and various salt crystals

FIGURE 9. Free surface velocities for $0.267 \mathrm{~mm}$ thick tantalum disks driven by $19.871 \mathrm{~mm}$ of LX-17

Since the chemical energy is released at some distance from the leading shock wave, all self-sustaining detonation waves are three-dimensional and consist of a complex system of Mach stem interactions of shock wavelets. The three-dimensional structures of homogeneous gaseous and liquid explosives are very regular and have been studied in great detail (40). Due to solid particle interactions and the presence of voids and binders, one expects the detonation front structure to be more complex and less regular in heterogeneous explosives than in homogeneous ones. The sub-nanosecond techniques needed to resolve this wave front structure are becoming available. The Non-Equilibrium Zeldovich- von Neumann - Doring (NEZND) theory of detonation (40) has been developed to quantify all of the non-equilibrium processes that precede and follow exothermic chemical reactions behind each wavelet of the three-dimensional structure comprising the reaction zone of a condensed phase detonation wave. Figure 10 illustrates many of these processes. Eventually all of these non-equilibrium physical and chemical mechanisms, plus perhaps others that have not yet been identified, need to be measured experimentally and modeled in advanced multidimensional reaction flow models. Then the interactions of shock waves with explosive molecules and vice versa can be better understood. This understanding may lead to the production of safer, more energetic explosive molecules and formulations.

FIGURE 10. The Non-Equilibrium Zeldovich - von Neumann- Doring (NEZND) model of detonation for condensed phase explosives

\section{FUTURE RESEARCH}

While a great deal has been learned in recent years about the interaction of impact, thermal, and shock processes with explosive molecules, greater spatial and time resolution is needed in shock wave experiments and calculations. For understanding low velocity impact ignition mechanisms, the relative roles of void collapse, friction, shear, dislocation pile-up, strain, etc. need to be determined by clever experimentation. Many of these postulated hot spot formation mechanisms depend upon the magnitude of the viscosity in and behind shock wave fronts, which has not yet been measured for shock waves in condensed phase explosives. If the dominant hot spot mechanism (or mechanisms) can be identified experimentally and successfully modeled, modifications to existing explosive formulations can be made. New processes and new materials (explosives, binders, additives, etc.) can be developed to produce safer products.

In the thermal explosion category, more detailed chemical kinetic data on the individual reactions that dominate the various possible decomposition pathways is needed. Then the current global reactions can be developed into more sophisticated chemical kinetic models that can follow the complete reactive flow and predict its violence.

Since chemical reaction rates are controlled by the local temperature of a region of molecules, the most important research area in impact ignition and shock initiation is experimental measurements of local temperatures in all regions of impacted and shocked explosives: in and around hot spots, in deflagration waves; in the reactive flows behind shock fronts and in detonation waves. With this type of data, improved equations of state and temperature based, statistical hot spot reactive flow models can be developed to better predict the effects of shock waves on explosive molecules and vice versa $(23,24)$. Eventually it will become possible to model impact and shock-induced reactions as thermal decomposition mechanisms are modeled today by identifying intermediate reaction product species and following their concentration changes. To do this effectively, nanosecond or faster time resolved experimental data on the rates of consumption of the unreacted explosive, the concentrations of intermediate species, and the rates of production of the final stable products is needed. Accurate determination of the three-dimensional structures of detonation waves in condensed phase explosives is required to determine the level of detail required in reactive flow models to yield more realistic simulations in two- and three-dimensional hydrodynamic codes.

\section{ACKNOWLEDGMENTS}

The authors would like to thank all of the excellent scientists that have taught us so much about explosives, especially Michael Cowperthwaite, Bob Woolfolk, Jerry Forbes, Paul Urtiew, Bud Hayes, LeRoy Green, Leroy Erickson, Jace Nunziato, Mel Baer, Ed Lee, Bill Davis, John Bdzil, and many others. 
This work was performed under the auspices of the U.S. Department of Energy by Lawrence Livermore National Laboratory (Contract No.W-7405-ENG-48).

\section{REFERENCES}

1. Dick, J. J., Martinez, A. R., and Hixson, R. S., Eleventh International Detonation Symposium, Office of Naval Research, ONR 33300-5, Aspen, CO, 1998, pp. 317-324.

2. Tarver, C., Urtiew, P., Chidester, S., and Green, L., Propellants, Explosives, Pyrotechnics 18, 117-127 (1993).

3. Field, J. E., Bourne, N. K., Palmer, S. J. P., and Walley, S. M., Phil. Trans. R. Soc. Lond. A 339, 269-299 (1992).

4. Chidester, S.K., Green, L.G., and Lee, C.G., "A Frictional Work Predictive Method for the Initiation of Solid High Explosives from Low Pressure Impacts," Tenth International Detonation Symposium, ONR 33395-12, Boston, MA 1993, pp. 785-792.

5. Chidester, S. K., Tarver, C. M., and Lee, C. G., "Impact Ignition of New and Aged Solid Explosives," Shock Compression of Condensed Matter-1997, edited by S.C. Schmidt et. al., AIP Conference Proceedings 429, AIP Press, New York, 1998, pp. 707-710.

6. Chidester, Steven K., Tarver, Craig M., and Garza, Raul, “Low Amplitude Impact Testing and Analysis of Pristine and Aged Solid High Explosives," Eleventh (International) Symposium on Detonation, ONR 33300-5, Arlington, VA, 1998, pp. 93-100.

7. Chidester, S. K., Tarver, C. M., DePiero, A. H., and Garza, R. G., "Single and Multiple Impact of New and Aged High Explosives in the Steven Impact Test," Shock Compression of Condensed Matter-1999, M.D. Furnish, L. C. Chhabildas, and R. S. Hixson, eds., AIP Conference Proceedings 505, New York, 2000, pp. 663 - 666.

8. Niles, A. M., Garcia, F., Greenwood, D. W., Forbes, J. W., Tarver, C. M., Chidester, S. K., Garza, R. G., and Switzer, L. L., "Measurement of Low Level Explosives Reaction in Gauged Multi-dimensional Steven Impact Tests," Shock Compression of Condensed Matter-2001, Furnish, M. D., Thadhani, N. N., and Horie, Y, eds. CP-620, AIP Press, New York, 2002, pp. 886-889.

9. Vandersall, K. S., Chidester, S. K., Forbes, J. W., Garcia, F., Greenwood, D. W., Switzer, L. L., and Tarver, C. M., "Experimental and Modeling Studies of Crush, Puncture, and Perforation Scenarios in the Steven Impact Test," Twelfth International Detonation Symposium, San Diego, CA, August 2002, in press.

10. Switzer, L. L., Vandersall, K. S., Chidester, S. K., Greenwood, D. W., and Tarver, C. M., "Threshold Studies of Heated HMX_Based Energetic Material Targets using the Steven Impact Test," Shock Compression of Condensed Matter-2003, Furnish, M. D., ed., AIP Press, New York, 2004, in press.

11. Vandersall, K. S., Murty, S. S., Chidester, S. K., Forbes, J. W., Garcia, F., Greenwood, D. W., and Tarver, C. M., "Investigation of Steven Impact Test using a Transportation Hook Projectile with Gauged Experiments and 3D Modeling," Shock Compression of Condensed Matter-2003, Furnish, M. D., ed., AlP Press, New York, 2004, in press.

12. Idar, D. J., Lucht, R. A., Straight, J. W., Scammon, R. J., Browning, R. V., Middleditch J., Dienes, J. K., Skidmore, C. B., and Buntain, G. A., Eleventh International Detonation Symposium, Aspen, CO, 1998, pp. 101 - 110.

13. Scammon, R. J., Browning, R. V., Middleditch, J., Dienes, J. K. Haverman, K. S., and Bennett, J. G., Eleventh International Detonation Symposium, Aspen, CO, 1998, pp. 111 - 118.

14. Browning, R. V., Shock Compression of Condensed Matter-1995, S. C. Schmidt and W. C. Tao, eds, AIP Press, New York, 1996, pp. 405 - 408.

15. Green, L. G., James, E., Lee. E. L., Chambers, E. S., Tarver, C. M., Westmoreland, C., Weston, A. M., and Brown, B., Seventh Symposium (International) on Detonation, Naval Surface Weapons Center MP82-334, Annapolis, MD, 1981, pp. $256-264$.

16. Chidester, S. K., Tarver, C. M., Green, L. G., and Urtiew, P. A., Combustion and Flame 110, 264 - 280 (1997).

17. Tarver, C. M., Hallquist, J. O., and Erickson, L. M., Eighth Symposium (International) on Detonation, Naval Surface Weapons Center NSWC MP86-194, Albuquerque, NM, 1985, pp. 951-961.

18. McGuire, R. and Tarver, C. M., Seventh Symposium (International) on Detonation, Naval Surface Weapons Center MP82334, Annapolis, MD, 1981,pp. $56-64$.

19. Tarver, C. M. and Tran, T. D., "Thermal Decomposition Models for HMX-based Plastic Bonded Explosives," Combustion and Flame, 2004, in press.

20. Maienschein, J. L. and Chandler, J. B., Eleventh International Detonation Symposium, Office of Naval Research, ONR 33300-5, Aspen, CO, 1998, pp. 872 - 880.

21. Esposito, A., Farber, D., Reaugh, J., and Zaug, J., Propellants, Explosives, Pyrotechnics 28, 83 - 88 (2003).

22. Foltz, M. F., Propellants, Explosives, Pyrotechnics 18, $210-216$ (1993).

23. Nichols, A. L. and Tarver, C. M. "A Statistical Hot Spot Reactive Flow Model for Shock Initiation and Detonation of Solid Explosives," Twelfth International Detonation Symposium, Office of Naval Research, San Diego, CA, August 2002, in press.

24. Nichols, A. L., Tarver, C. M. and McGuire, E. M., "ALE3D Statistical Hot Spot Model Results for LX-17,"in Shock Waves in Condensed Matter-2003, M. D. Furnish, ed., AIP Press, 2004, in press.

25. Reaugh, J. E., "Grain Scale Dynamics in Explosives," LLNL Report UC-ID-150388, September 2002.

26. Wardell, J. and Maienschein, J., "The Scaled Thermal Explosion Experiment," Twelfth International Detonation Symposium, Office of Naval Research, San Diego, CA, August 2002, in press.

27. Garcia, F., Forbes, J. W., Tarver, C. M., Urtiew, P. A., Greenwood, D. W., and Vandersall, K. S.,"Measurement of Low Level Explosives Reaction in Gauged Multi-dimensional Steven Impact Tests," Shock Compression of Condensed Matter2001, Furnish, M. D., Thadhani, N. N., and Horie, Y, eds. CP-620, AIP Press, New York, 2002, pp. $882-885$.

28. Forbes, J. W., Garcia, F., Tarver, C. M., and Greenwood, D. W., "Pressure Wave Measurements during Thermal Explosion of HMX-Based High Explosives," Twelfth International Detonation Symposium, Office of Naval Research, San Diego, CA, August 2002, in press.

29. Garcia, F., Vandersall, K. S., Forbes, J. W., Tarver, C. M., and Greenwood, D. W., "Pressure Wave Measurements Resulting from Thermal Cook-off of the HMX-Based High Explosive LX-04," Shock Waves in Condensed Matter-2003, M. D. Furnish, ed., AIP Press, 2004, in press.

30. Tarver, C. M., Chidester, S. K. and Nichols, A. L., J. Phys. Chem. 100, $5794-5799$ (1996).

31. Campbell, A. W. and Travis, J. R., Eighth Symposium (International) on Detonation, Naval Surface Weapons Center NSWC MP 86-194, Albuquerque, NM, 1985, pp. 1057 - 1068.

32. Tarver, C. M., Cook, T. M., Urtiew, P. A., and Tao, W. C., Tenth Symposium (International) on Detonation, Office of Naval Research ONR 33395-12, Boston, MA, 1993, pp. 696 - 703.

33. Yoh, J. J. and McClelland, "Simulating the Thermal Response of High Explosives on Time Scales of Days to Microseconds," in Shock Waves in Condensed Matter-2003, M. D. Furnish, ed., AIP Press, 2004, in press.

34. Gustavsen, R. L., Sheffield, S. A., and Alcon, R. R., Tarver, C. M., Forbes, J. W., and Garcia, F., in Shock Compression of Condensed Matter-2001, N. N. Thadhani and Y. Horie, eds., AIP Press, 2002, pp. 1019 - 1022. 
35. Sheffield, S. A., Gustavsen, R. L., Hill, L. G., and Alcon, R. R., Eleventh International Detonation Symposium, Office of Naval Research, ONR 33300-5, Aspen, CO, 1998, pp. 451-458.

36. Gustavsen, R. L., Sheffield, S. A., and Alcon, R. R., Eleventh International Detonation Symposium, Office of Naval Research, ONR 33300-5, Aspen, CO, 1998, pp. 821 - 827.

37. Tarver, C. M., Forbes, J. W., Garcia, F., and Urtiew, P. A., Shock Compression of Condensed Matter-2001, N. N. Thadhani and Y. Horie, eds., AIP Press, 2002, pp. 1043 - 1046.

38. Tarver, C. M., Kury, J. W., and Breithaupt, R. D., J. Appl. Phys. 82, $3771-3782$ (1997).

39. Kury, J. W., Breithaupt, R. D., and Tarver, C. M., Shock Waves 9, 227 - 237 (1999).

40. Tarver, C. M. J. Phys. Chem. 101, 4845 - 4851 (1997). 


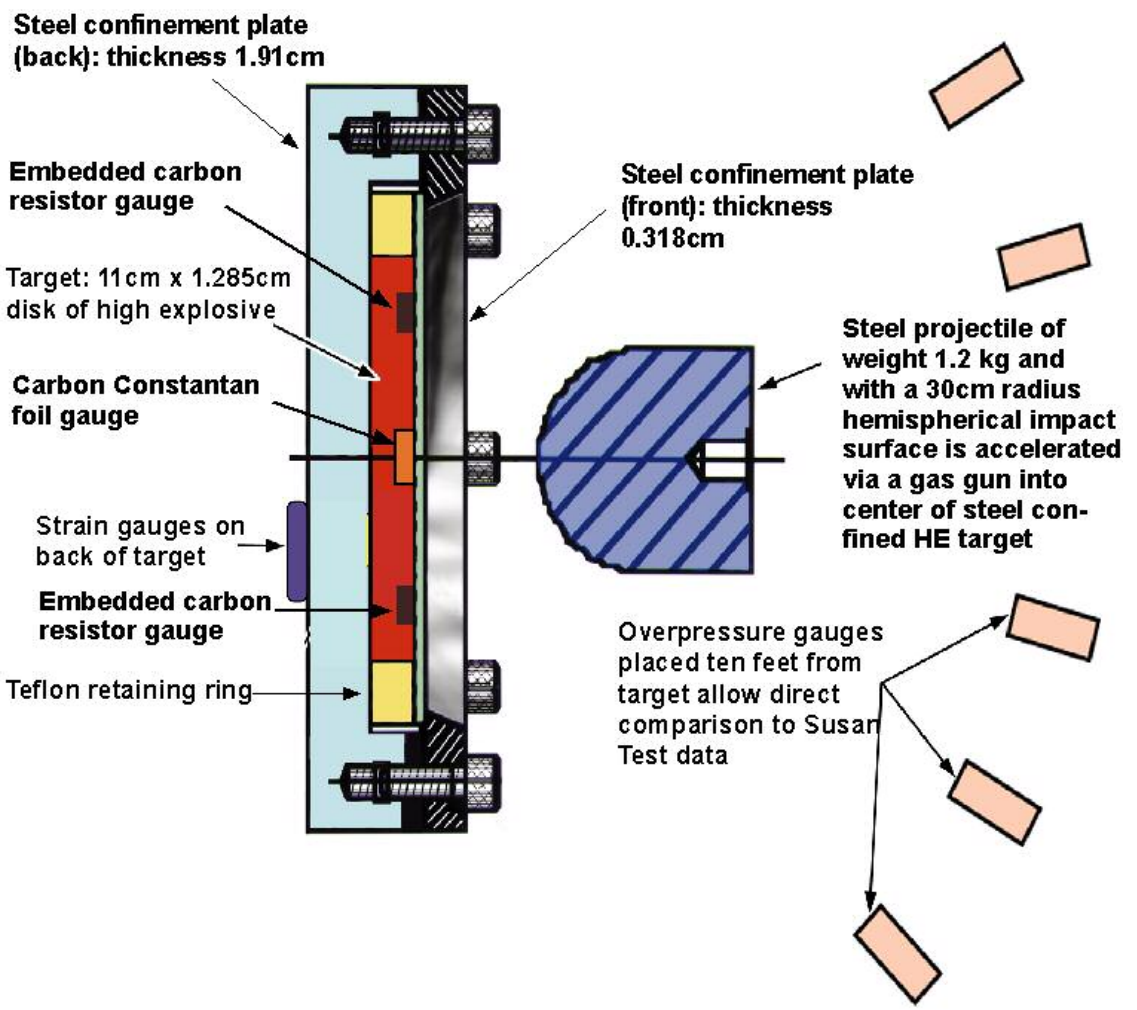

FIGURE 1. Geometry of the LLNL Steven Impact Test 


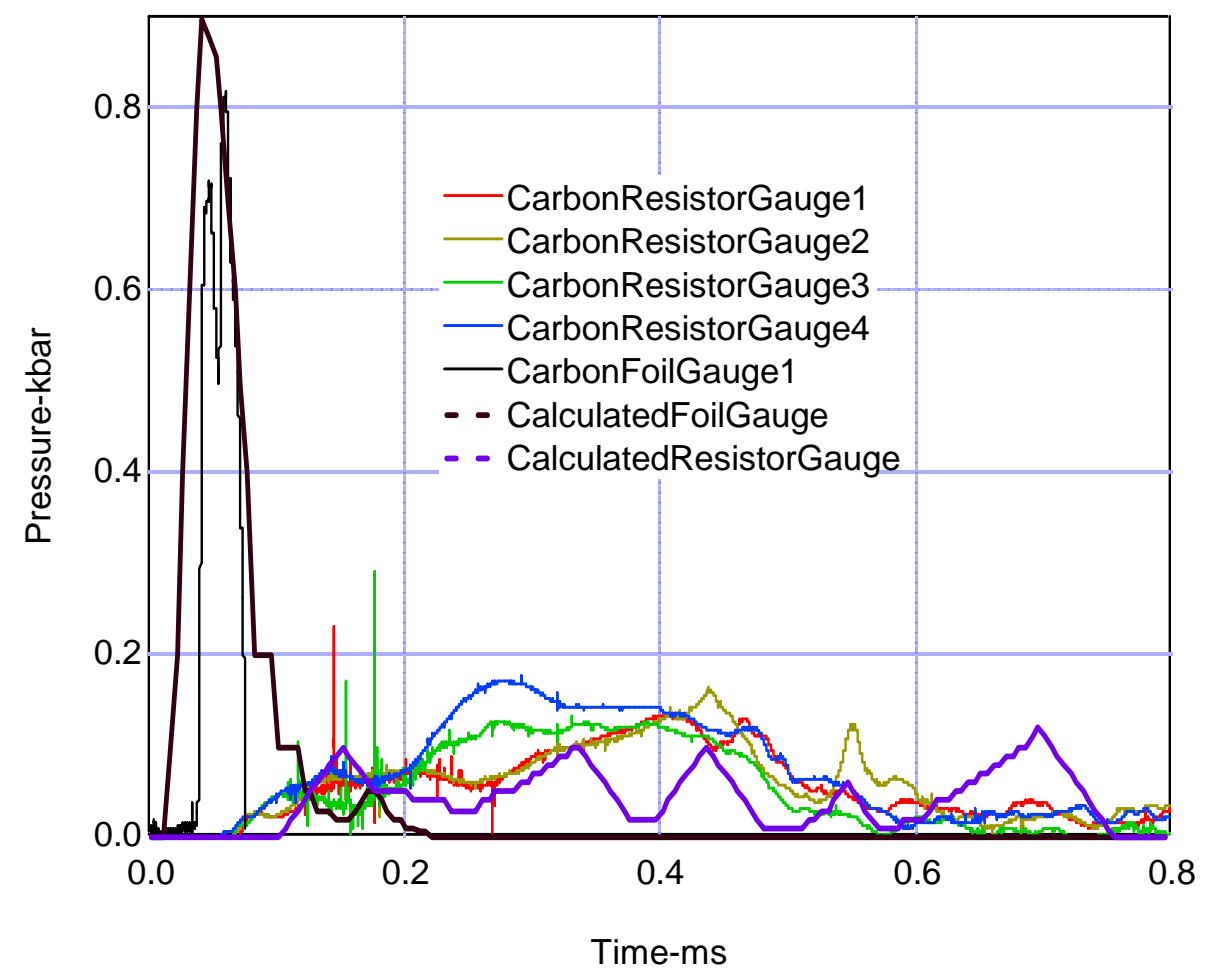

FIGURE 2. Experimental and calculated pressure histories in a PBX 9501 Steven Test target impacted at $51.36 \mathrm{~m} / \mathrm{s}$ (no reaction) 


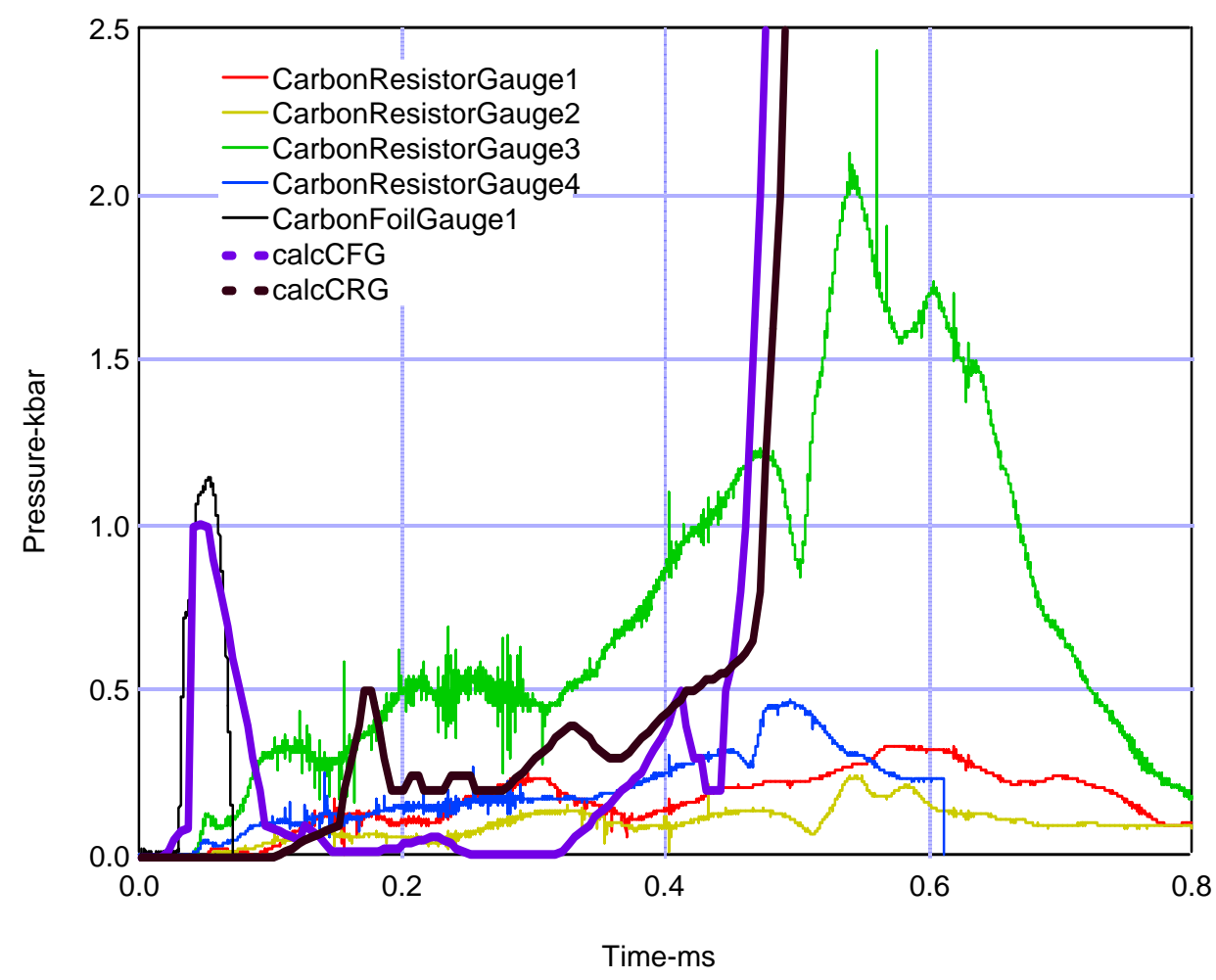

FIGURE 3. Experimental and calculated pressure histories in a PBX 9501 Steven Test target impacted at $55.40 \mathrm{~m} / \mathrm{s}$ (reaction) 


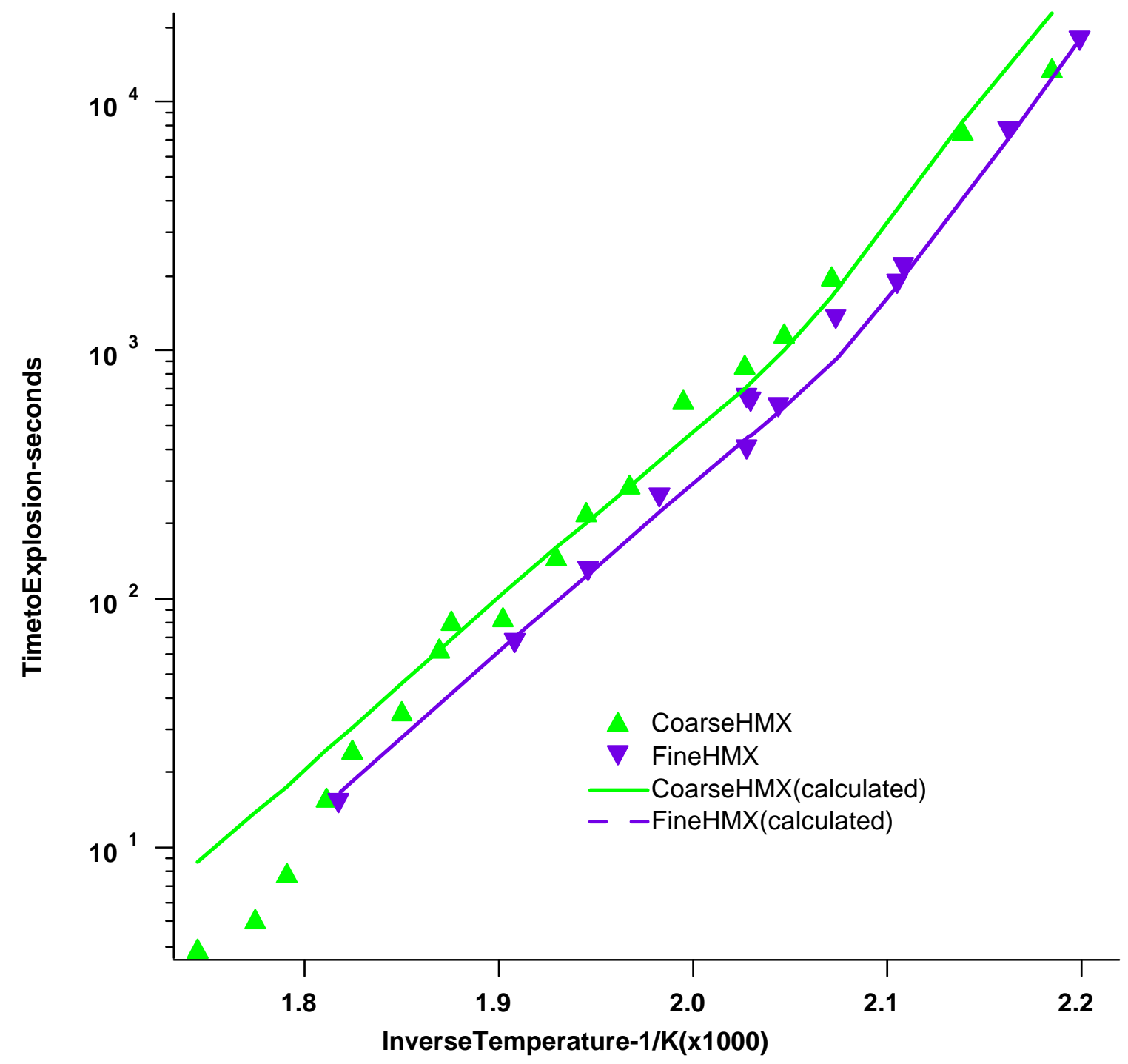

FIGURE 4. ODTX Experimental and Calculated Times to Explosion versus Inverse Temperature for Coarse and HMX 

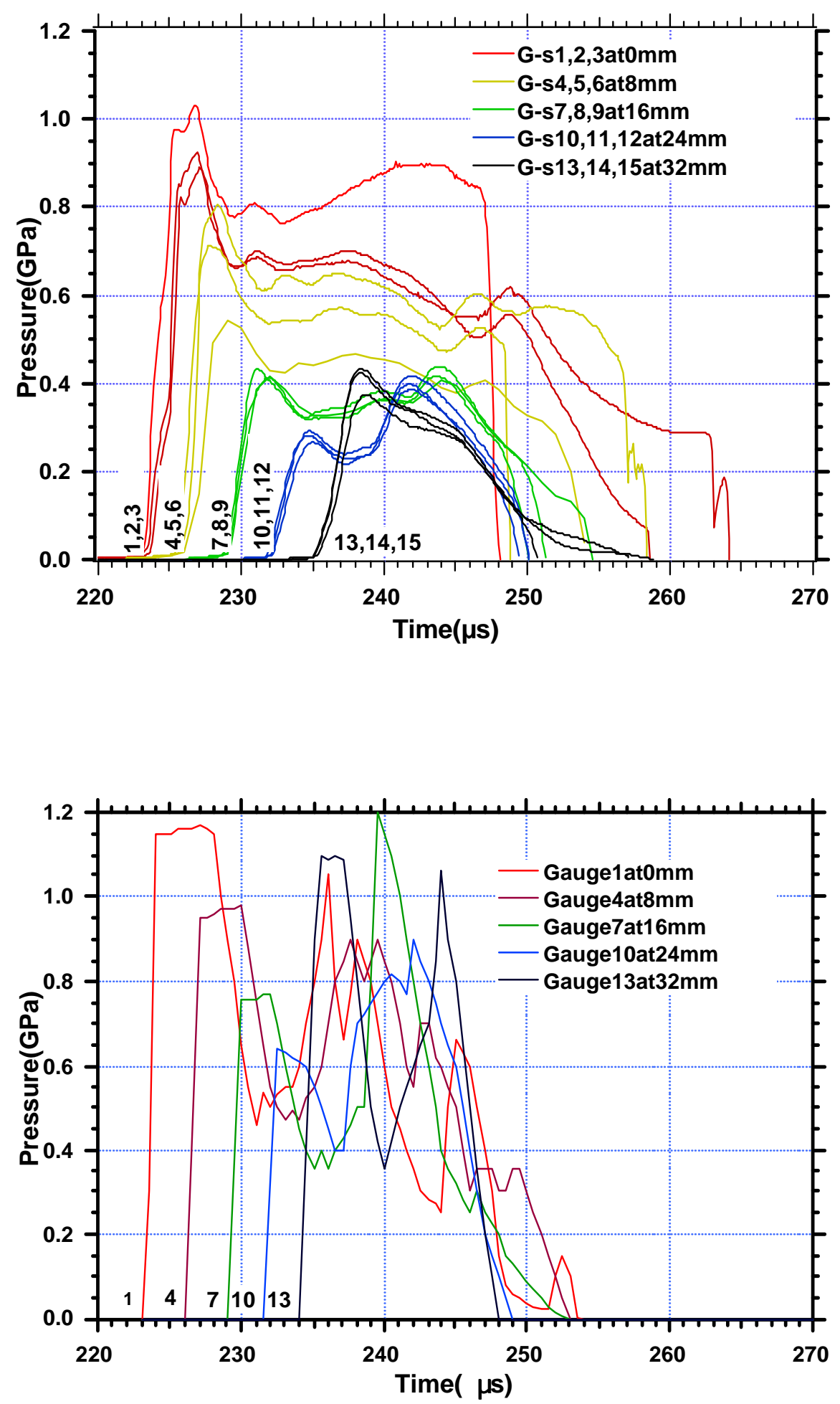

Figure 5. Experimental (upper) and calculated (lower) pressure histories in a PBX 9501 Jerry Test acceptor charge 


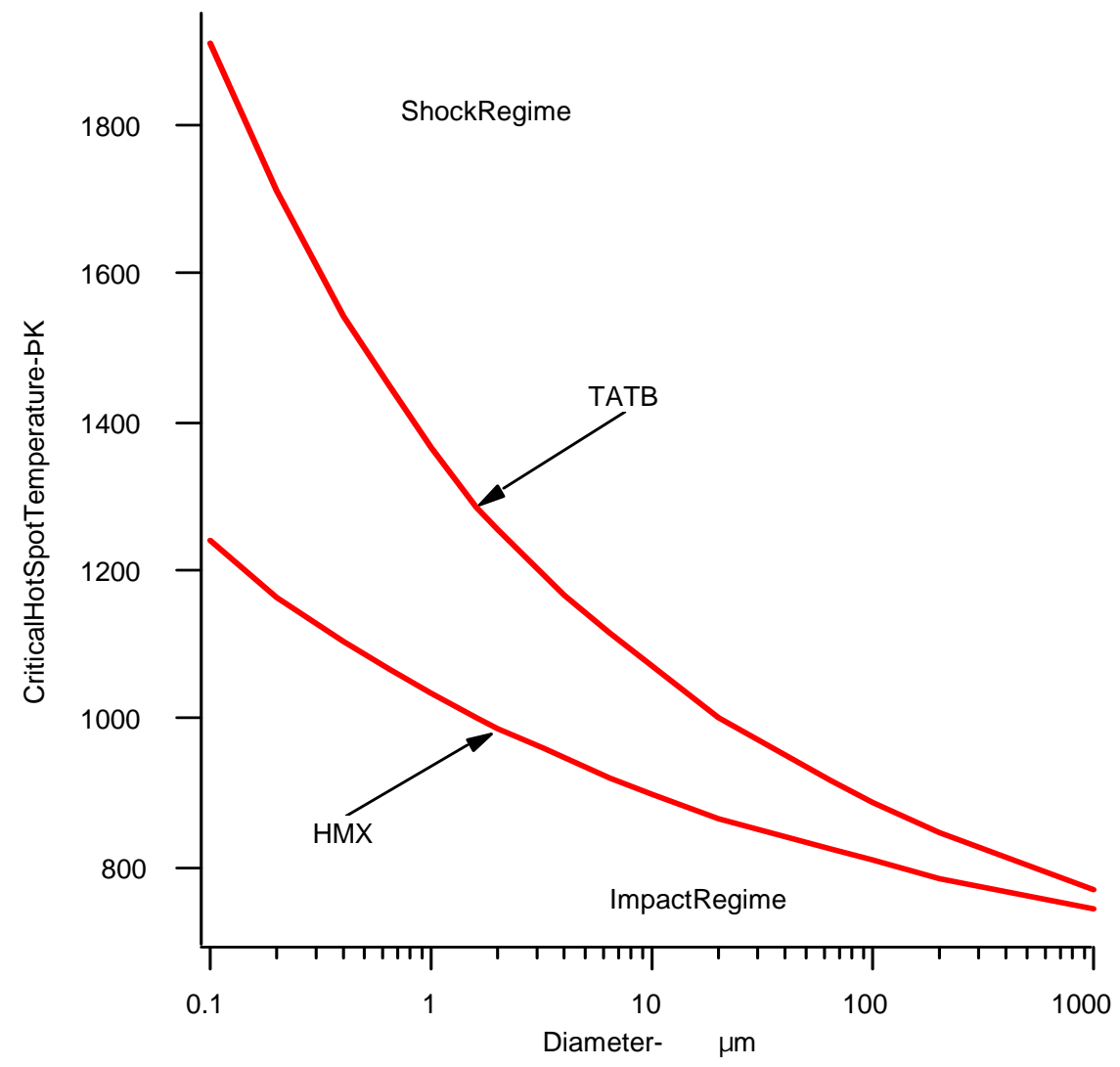

FIGURE 6. Critical spherical hot spot temperatures in HMX and TATB at various diameters 


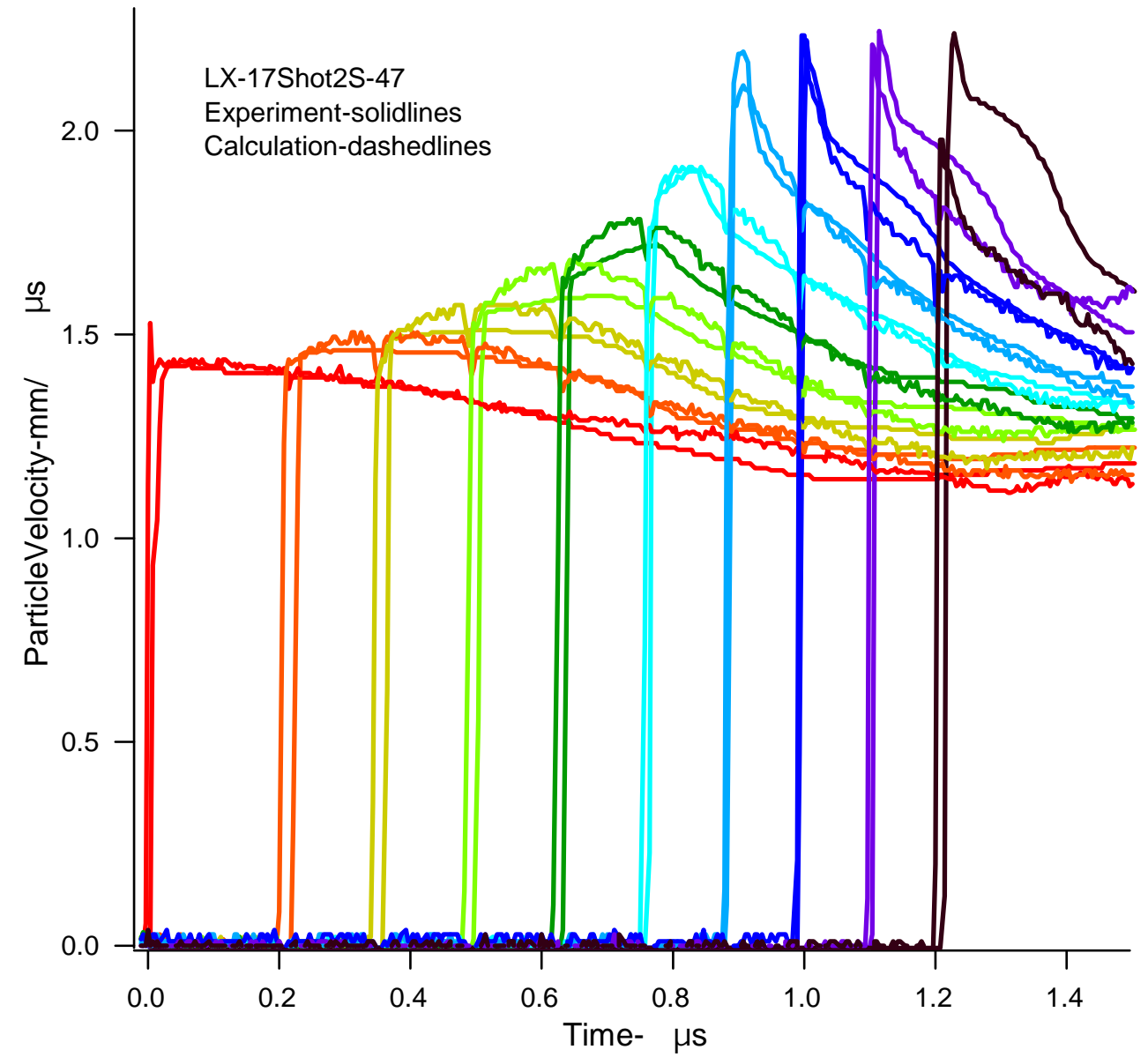

FIGURE 7. Particle velocity histories for LX-17 shock initiated by a Kel-F flyer plate at $2.951 \mathrm{~mm} / \mu \mathrm{s}$ 


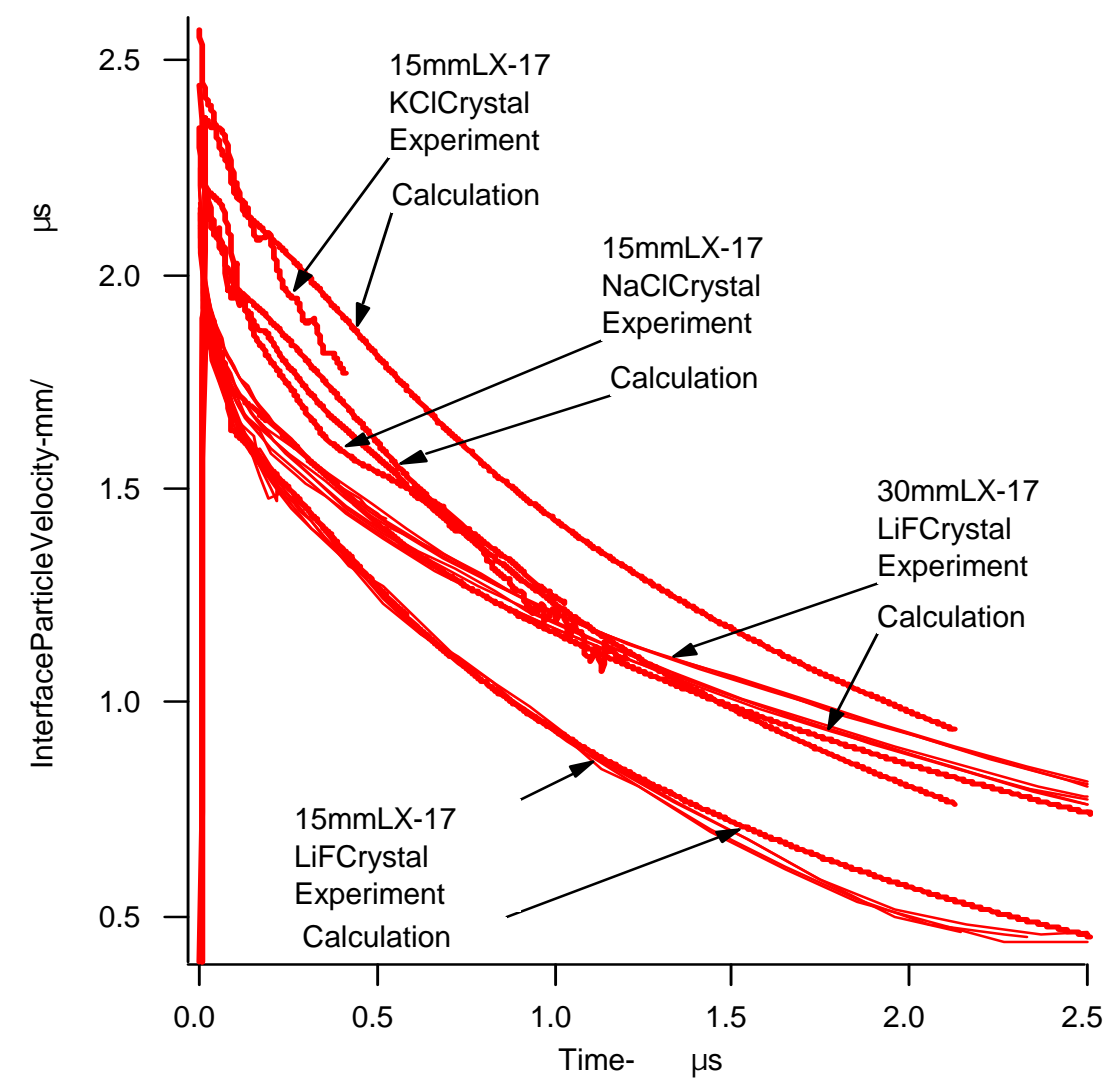

FIGURE 8. Interface particle velocity histories for detonating LX-17 and various salt crystals 


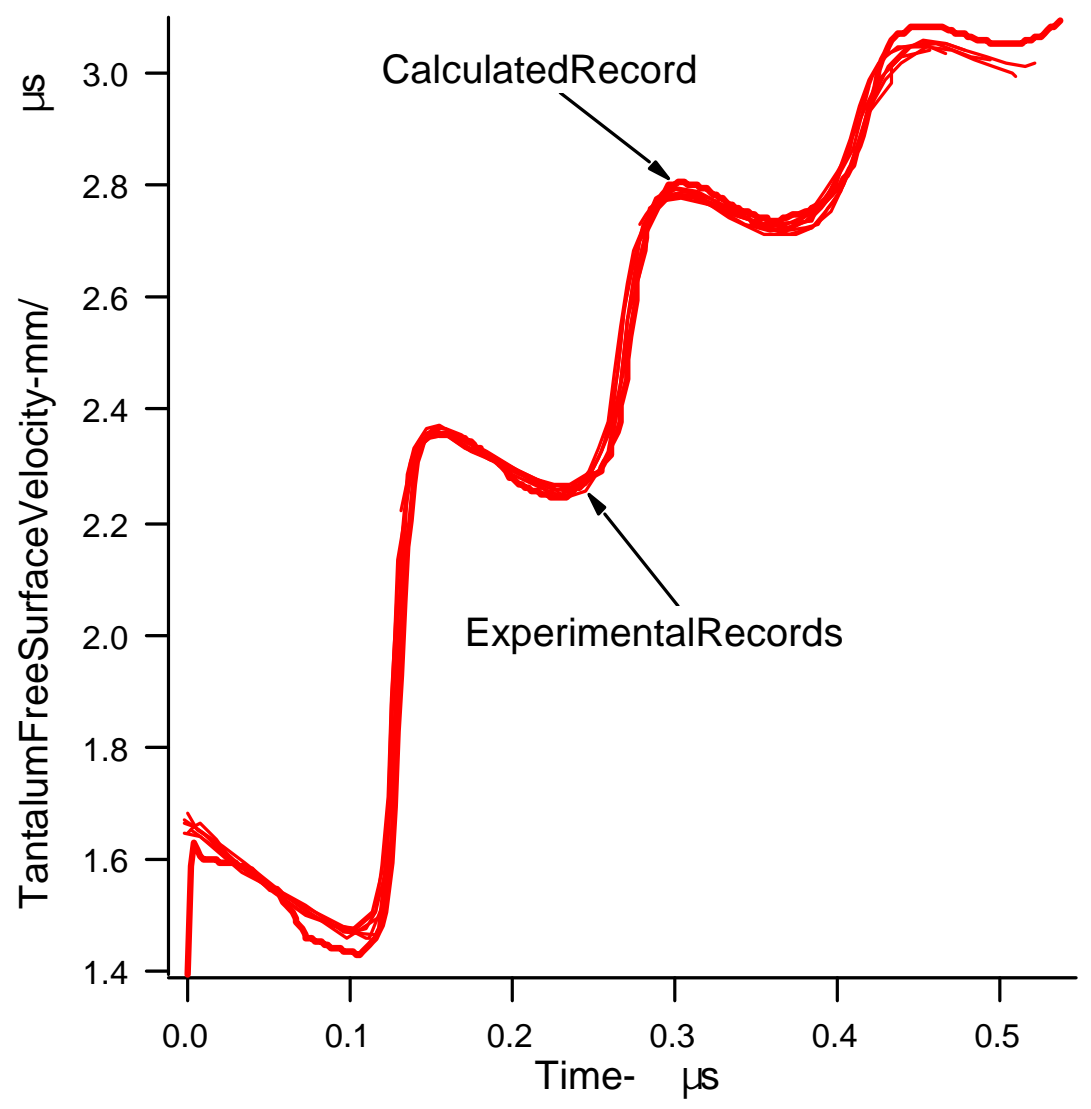

FIGURE 9. Free surface velocities for $0.267 \mathrm{~mm}$ thick tantalum disks driven by $19.871 \mathrm{~mm}$ of LX-17 


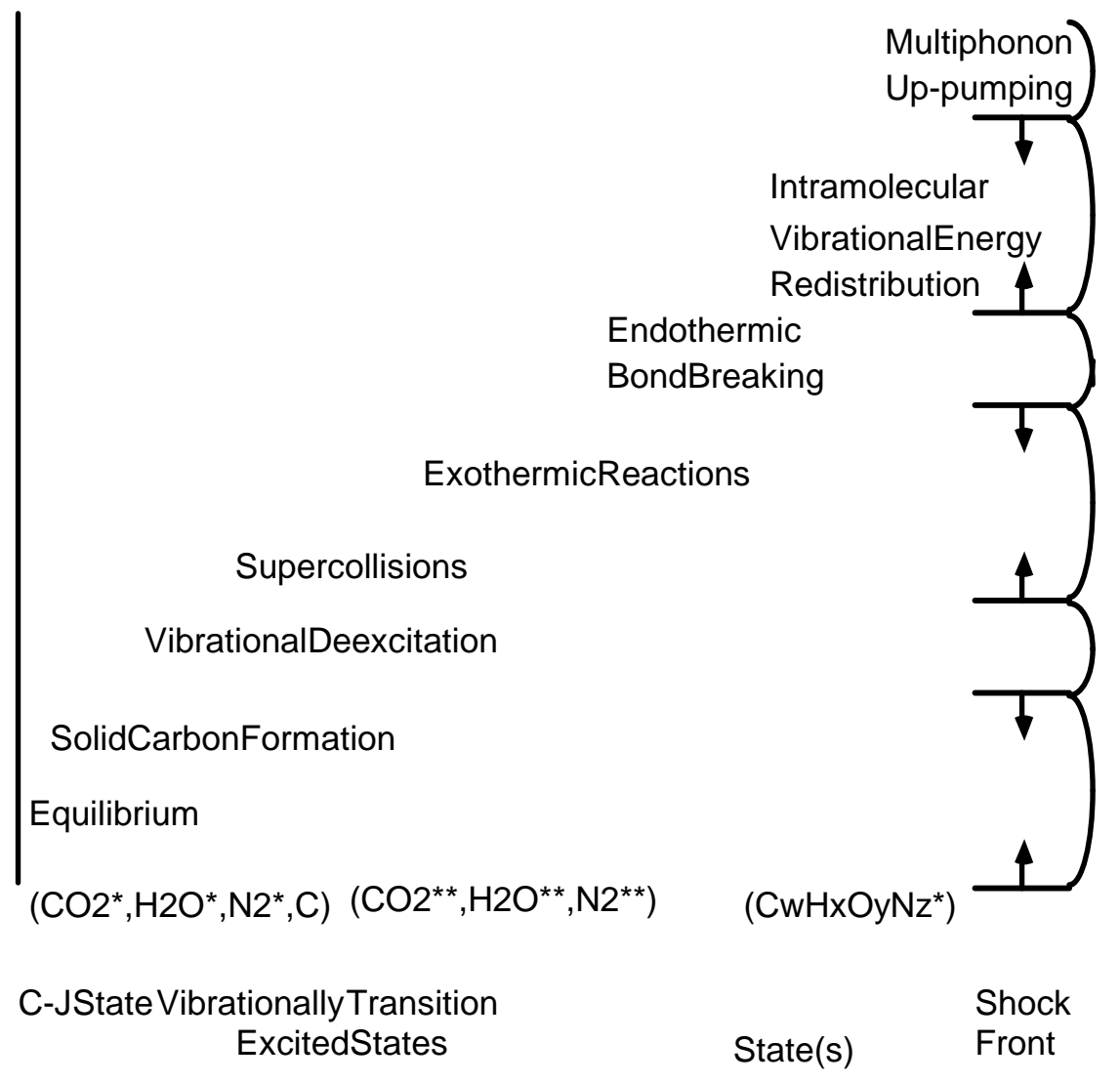

FIGURE 10. The Non-Equilibrium Zeldovich - von Neumann- Doring (NEZND) model of detonation for condensed phase explosives 